\title{
Acceptability of a herd immunity-focused, transmission-blocking malaria vaccine in malaria-endemic communities in the Peruvian Amazon: an exploratory study
}

Sara E. White ${ }^{1}$, Steven A. Harvey²*, Graciela Meza ${ }^{3}$, Alejandro Llanos ${ }^{4}$, Mitchel Guzman ${ }^{4}$, Dionicia Gamboa ${ }^{4,5}$ and Joseph M. Vinetz ${ }^{1,4,5^{*}}$

\begin{abstract}
Background: A transmission-blocking vaccine (TBV) to prevent malaria-infected humans from infecting mosquitoes has been increasingly considered as a tool for malaria control and elimination. This study tested the hypothesis that a malaria TBV would be acceptable among residents of a malaria-hypoendemic region.

Methods: The study was carried out in six Spanish-speaking rural villages in the Department of Loreto in the Peruvian Amazon. These villages comprise a cohort of 430 households associated with the Peru-Brazil International Centre for Excellence in Malaria Research. Individuals from one-third (143) of enrolled households in an ongoing longitudinal, prospective cohort study in 6 communities in Loreto, Peru, were randomly selected to participate by answering a prevalidated questionnaire.
\end{abstract}

Results: All 143 participants expressed desire for a malaria vaccine in general; only 1 (0.7\%) expressed unwillingness to receive a transmission-blocking malaria vaccine. Injection was considered most acceptable for adults (97.2\%); for children drops in the mouth were preferred (96.8\%). Acceptability waned marginally with the prospect of multiple injections (83.8\%) and different projected efficacies at 70 and 50\% (90.1 and 71.8\%, respectively). Respondents demonstrated clear understanding that the vaccine was for community, rather than personal, protection against malaria infection.

Discussion: In this setting of the Peruvian Amazon, a transmission-blocking malaria vaccine was found to be almost universally acceptable. This study is the first to report that residents of a malaria-endemic region have been queried regarding a malaria vaccine strategy that policy-makers in the industrialized world often dismiss as altruistic.

Keywords: Malaria, Transmission-blocking vaccine (TBV), Social acceptability, Peru, Amazon

\footnotetext{
*Correspondence: steven.harvey@jhu.edu; jvinetz@ucsd.edu

1 Division of Infectious Diseases, Department of Medicine, University of California, San Diego School of Medicine, 9500 Gilman Drive 0760, Biomedical Research Facility Room 4A16, La Jolla, CA 92093-0760, USA

2 Department of International Health, Johns Hopkins Bloomberg School

of Public Health, 615 N. Wolfe St. E5030, Baltimore, MD 21205, USA

Full list of author information is available at the end of the article
} 


\section{Background}

Proof of concept of a malaria transmission-blocking vaccine (TBV) to block the transmission of malaria from human host to mosquito vector was first demonstrated in two landmark studies in the 1970s [1, 2]. From almost the very start, the essential concept of a TBV has been considered-and sometimes dismissed as-altruistic, or only as adjunct to an anti-infection or anti-disease vaccine [3, 4]. A recent review, however, noted the compelling ethical justification of the potential deployment of a highly safe and effective TBV because malaria control, elimination, and eradication are sufficiently important public health goals [5].

Pfs25, first reported in 1988, is the leading antigen candidate for a TBV [6-20], although other candidates are also under development [21]. A purely transmissionblocking vaccine would not directly confer protection against malarial disease to the recipient. Instead, it would prevent infection of the vector by stimulating antibody production against mosquito-infective forms, such as gametocytes, zygotes, and ookinetes. Antibodies would be taken up along with an infectious blood meal and would inhibit further parasite development within the mosquito. Thus, a TBV would prevent infection of mosquitoes, resulting in reduced transmission at the population level [22-28].

Such a concept seems more relevant today amid the increasingly widespread realization that herd immunity in populations does not need to focus solely on prevention of the recipient from becoming infected. This principle has been cited as an antecedent justification for a malaria TBV based, for example, on vaccines against measles [29], rubella [29], human papilloma virus [30], and polio [4]. Even in proposed HIV vaccination strategies, the public health emphasis includes a clear focus on preventing individuals from spreading infection [31]. Regardless, a key gap remains in developing a malaria TBV: to understand whether malaria-affected populations would be willing to accept a vaccine that conferred no direct personal protection.

The end of indoor residual spraying with DDT in the 1990s was followed by an epidemic rise in malaria in the Peruvian Amazon [32-34]. This was followed in turn by a deceptively promising decline in overall incidence, resulting in a stable state of hypoendemic transmission. Recent years have seen continued hyperendemicity, rises in Plasmodium vivax incidence, epidemic Plasmodium falciparum outbreaks (Peruvian Ministry of Health, unpublished data), and unexpectedly high levels of subclinical and sub patent cases [35-37]. All this suggests that in the long term, prevailing preventive measures $[32,33]$ may not be sufficient to control, much less eliminate, malaria in this region [38-40]. For instance, the effectiveness of long-lasting insecticide-impregnated bed nets (LLINs) is potentially limited by mosquito behavioural changes in response to net use [41], despite data suggesting that Amazonian vectors remain susceptible to standard insecticides in the region [42]. Test-andtreat strategies only identify clinical cases of malaria, but do not eliminate the asymptomatic reservoir of infection [43]. Other malaria-endemic areas in Amazonia $[36,44]$ and around the world have seen similar trends [45-47]. It is widely agreed that an effective malaria vaccine would be an important tool to contribute towards regional and global malaria control and elimination [32, $33,37,48-50]$.

TBV development to date has largely assumed that the focus-manifested most recently as the target product profile-would be on preventing infected individuals from infecting vectors in proximity to their local family members or close neighbours where there is anophelism [21]. Recently enhanced insight into how human mobility contributes to maintaining and spreading malaria infections in regions and among populations brings new justification for deploying a TBV, since vaccine recipients with asymptomatic parasitaemia would be prevented from transmitting their parasites to mosquitoes both in their home villages and when moving or travelling to other places [51-56]. No previous study has been published that measures the attitudes of people living in malaria-endemic regions about the general concept of a TBV. This study tested the hypothesis that people living in malaria-hypoendemic communities in the Peruvian Amazon would be able to understand the concept of, and be willing to receive, a transmission-blocking malaria vaccine for themselves and their children. Data to support such a finding would provide important justification and impetus for further TBV development.

\section{Methods}

\section{Human subjects approvals}

This study was approved by the Comité Institucional de Ética (CIE) of the Universidad Peruana Cayetano Heredia, by the Human Research Protections Program of the University of California, San Diego, and by the Dirección Regional de Salud (DIRESA) of the Regional Government of Loreto. The surveyor explained to each participant that his or her participation was voluntary and confidential, and each signed an informed consent. The surveys do not include any identifying information.

\section{Study population}

The study was carried out among a population of 4000 in six Spanish-speaking rural villages in the Loreto Department of the Peruvian Amazon in northeastern Peru, the general and geographic characteristics of which have 
been previously described $[57,58]$. The prevalence of malaria parasitaemia in this region ranges from 3 to $10 \%$ [40]. The entire region of northeastern Peru experiences approximately 60,000 cases of malaria annually $[40,58]$, with an approximate 5:1 ratio of $P$. vivax to $P$. falciparum [40]. The study communities of San Pedro, Santa Rita, and San José de Lupuna are located along the Nanay River; Cahuide, La Habana, and 12 de Abril are located roughly 56 kilometres Southwest of Iquitos along the Iquitos-Nauta highway. The study cohorts based here are part of the Peru-Brazil International Centre for Excellence in Malaria Research (ICEMR) programme.

\section{Study design and sample size estimates}

The parent malaria cohort from which the present study participants were drawn includes 430 numbered households. For feasibility, a sampling rate of $1 / 3$ was determined, yielding a total of 143 households; a formal sample size calculation was not done because of uncertainty about assumptions and outcomes. Retrospective calculations indicated that a sample size of 204 would have been required to estimate a true population acceptability rate of $50 \%$ when applying a finite population correction and permitting a 5\% margin of error. Although this would have been the most conservative sample size possible, our sample size of 143 was still sufficiently large to estimate a true population-wide rate of TBV acceptance of $84 \%$ or higher with a 5\% margin of error. Given this point estimate of $99.3 \%$, the study's sample size is reasonable.

The initial household was selected at random and every third numbered household after it was identified for participation. The head of household, male or female, answered the questionnaire, with the pair answering jointly if desired. Participants were required to be at least 18 years of age. If, after visiting a house on at least two occasions, the head of household was not present, an adult-child was permitted to answer. None of the families approached for participation refused. However, in approximately 20 cases neither a head of household nor an adult-child was present after two visits, so the subsequent listed household was approached instead. Approximately five of these visits were likewise unsuccessful, so respondents at the household prior to the first were sought. This method always elicited a willing participant; the originally determined sample size of 143 did not change as a result.

\section{Questionnaire format}

A quantitative questionnaire was designed to assess the acceptability of a transmission-blocking malaria vaccine for community members, both adults and children.
Questions were also included to evaluate changes in acceptability given differences in vaccine cost and efficacy, mode of administration, and potential need for multiple doses. One open-ended question was included to assess respondents' rationale for accepting or rejecting a transmission-blocking malaria vaccine.

The questionnaire was pre-validated by 12 members of the community of Cahuide using a qualitative group interview format similar to a focus group. The individual consent form and each question were read to the group and the intended meaning expressed. The group was then given the opportunity to suggest alternative ways of phrasing any ambiguous wording. Their suggestions were integrated into the final version of the questionnaire. Individuals involved in questionnaire validation were not eligible to be selected as respondents during data collection.

The questionnaire included 24 questions and required approximately $10 \mathrm{~min}$ to complete. Since many respondents were unable to read or write, the investigator administered the questionnaire orally. A Peruvian ICEMR staff member, already well-known to community residents, was present at every interaction. Respondents provided demographic information, including age, gender, occupation, religion, and education level. Respondents were asked about their and their children's experience with malaria, current prevention practices, and past vaccination history. Before inquiring about willingness to receive a transmission-blocking malaria vaccine, the questionnaire explained the concept as follows (translated from Spanish):

\section{'A traditional vaccine prevents you from contract- ing the illness. But malaria isn't a traditional illness because it is transmitted from a person to mosquito and then from that mosquito to another person, not simply from person to person like some other dis- eases. So imagine that there was a malaria vaccine, but it wouldn't prevent you from getting malaria. Instead it would prevent the mosquitoes that bite you from getting malaria and transmitting it to other people. In other words, even after getting the vaccine, you could still get sick with malaria, but you would no longer pass it on to others in your com- munity.}

Respondents were then asked whether they would be willing to receive such a vaccine and have it administered to their children. Finally, queries were made to the respondents whether their willingness would change depending on cost, efficacy, number of doses required, and mode of administration. All participants were free to ask questions at any time or ask for clarification of 
any question. Because of the pre-validation process the questionnaire was generally well-understood; however, the question regarding percent efficacy occasionally caused confusion among participants and required clarification. The concept was always explained as follows: " $70 \%$ efficacy means that if you give the vaccine to 100 people, it only works in 70 of them, and they no longer transmit malaria. But in the other 30 people, the vaccine does not work, and they continue to pass on malaria to the mosquitoes that bite them." The questionnaire is provided in Additional files 1 and 2.

\section{Results}

A total of 143 participants were surveyed among the six communities (Table 1 ). The majority (62\%) were women; male heads of household were frequently working outside of the home when their household was approached. A wide range of ages was represented across all communities, from 18 to 78. Almost all (96\%) had children, with $76 \%$ still living with children in their homes. Agriculture and homemaking were the most common occupations and Catholicism the predominant religion. The majority $(86 \%)$ of respondents had no formal education

Table 1 Demographics of the study participants

\begin{tabular}{|c|c|c|c|c|c|c|c|}
\hline & Cahuide & 12 de Abril & La Habana & San José de Lupuna & Santa Rita & San Pedro & Total \\
\hline \multicolumn{8}{|l|}{ Total households surveyed } \\
\hline & 48 & 17 & 13 & 28 & 22 & 15 & 143 \\
\hline \multicolumn{8}{|l|}{ Gender } \\
\hline Men & 14 & 9 & 7 & 10 & 10 & 5 & 55 \\
\hline Women & 34 & 8 & 6 & 18 & 12 & 10 & 88 \\
\hline \multicolumn{8}{|l|}{ Age } \\
\hline $18-30$ & 14 & 3 & 4 & 7 & 2 & 3 & 33 \\
\hline $31-40$ & 8 & 4 & 3 & 8 & 7 & 2 & 32 \\
\hline $41-50$ & 7 & 4 & 2 & 3 & 6 & 3 & 25 \\
\hline $51-60$ & 10 & 1 & 1 & 5 & 2 & 2 & 21 \\
\hline $61-70$ & 6 & 2 & 3 & 3 & 1 & 4 & 19 \\
\hline $71+$ & 3 & 3 & 0 & 2 & 4 & 1 & 13 \\
\hline \multicolumn{8}{|l|}{ Household characteristics } \\
\hline Childless & 3 & 0 & 2 & 1 & 0 & 0 & 6 \\
\hline Average number of children (range) & $4.6(0-14)$ & $4.8(1-9)$ & $4.3(0-9)$ & $3.6(0-10)$ & $4.4(2-7)$ & $5(1-9)$ & $4.4(0-14)$ \\
\hline $\begin{array}{l}\text { Households living with children } \\
<18 \text { years }\end{array}$ & 37 & 12 & 12 & 22 & 15 & 11 & 109 \\
\hline Average household size (range) & $4.4(1-9)$ & $5.2(1-13)$ & $5(2-9)$ & $4.1(2-7)$ & $4.4(1-8)$ & $4.7(1-12)$ & $4.5(1-13)$ \\
\hline \multicolumn{8}{|l|}{ Occupation } \\
\hline Agriculture & 21 & 10 & 8 & 9 & 14 & 6 & 68 \\
\hline Homemaker & 19 & 5 & 3 & 14 & 7 & 7 & 55 \\
\hline Carpentry & 1 & 1 & 0 & 1 & 0 & 0 & 3 \\
\hline Sales & 3 & 1 & 0 & 1 & 0 & 0 & 5 \\
\hline Other & 4 & 0 & 2 & 3 & 1 & 2 & 12 \\
\hline \multicolumn{8}{|l|}{ Religion } \\
\hline Catholic & 24 & 11 & 5 & 15 & 10 & 14 & 79 \\
\hline Evangelical & 14 & 4 & 3 & 9 & 6 & 1 & 37 \\
\hline None & 6 & 1 & 5 & 3 & 1 & 0 & 16 \\
\hline Other & 4 & 1 & 0 & 1 & 5 & 0 & 11 \\
\hline \multicolumn{8}{|l|}{ Education level } \\
\hline No school & 7 & 1 & 0 & 0 & 0 & 0 & 8 \\
\hline Primary incomplete & 16 & 7 & 6 & 12 & 13 & 6 & 60 \\
\hline Primary complete & 6 & 3 & 2 & 5 & 3 & 2 & 21 \\
\hline Secondary incomplete & 12 & 5 & 3 & 6 & 1 & 7 & 34 \\
\hline Secondary complete & 7 & 1 & 2 & 3 & 5 & 0 & 18 \\
\hline Some university & 0 & 0 & 0 & 2 & 0 & 0 & 2 \\
\hline
\end{tabular}



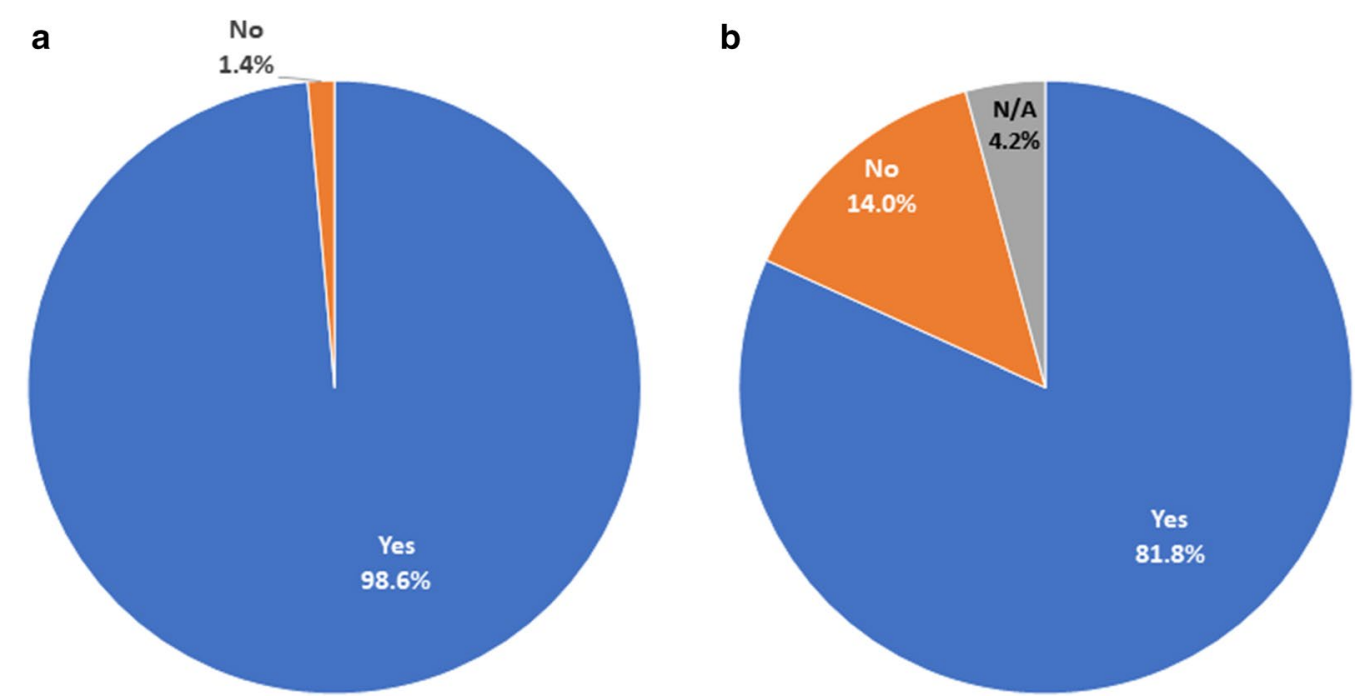

Fig. 1 Participants' answers about whether they (a) or any of their children (b) have ever had malaria. The number of participants was 143
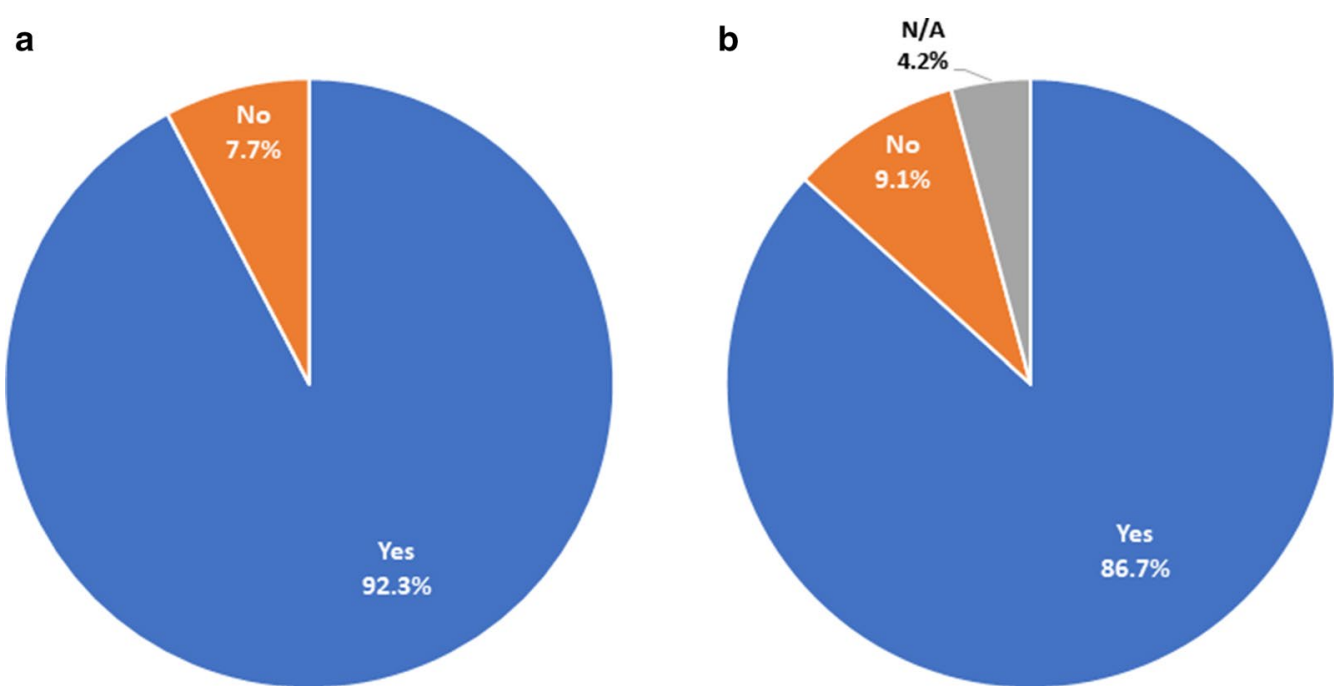

Fig. 2 Participants' answers about whether they (a) or any of their children (b) have ever received a vaccine. The number of participants was 143

or terminated their studies before completing secondary school.

Participants were asked about their own experience with malaria and that of their children (applicable for 137 respondents). Only 2 participants reported never having malaria (1.4\%), and the vast majority $(117,85.4 \%)$ reported at least one child who had had malaria (Fig. 1).

Because acceptability of a malaria vaccine might be influenced by a community's general culture of vaccine acceptance or non-acceptance, study participants were asked if they and any of their children had ever received any vaccine against another illness and were asked to list those they could remember. Most participants reported that they $(131,92.3 \%)$ and their children $(124,90.5 \%)$ had received at least one vaccine, with yellow fever, tetanus, varicella, and hepatitis the most commonly cited (Fig. 2).

Before the mention of a transmission-blocking vaccine, participants were asked whether they desired a malaria vaccine (Fig. 3). All 143 responded that they did. After the explanation of a transmission-blocking vaccine, participants were asked whether they would be willing to receive such a vaccine against malaria. All but one $(99.3 \%)$ responded that they would. When asked the same question for their children, the same participant 

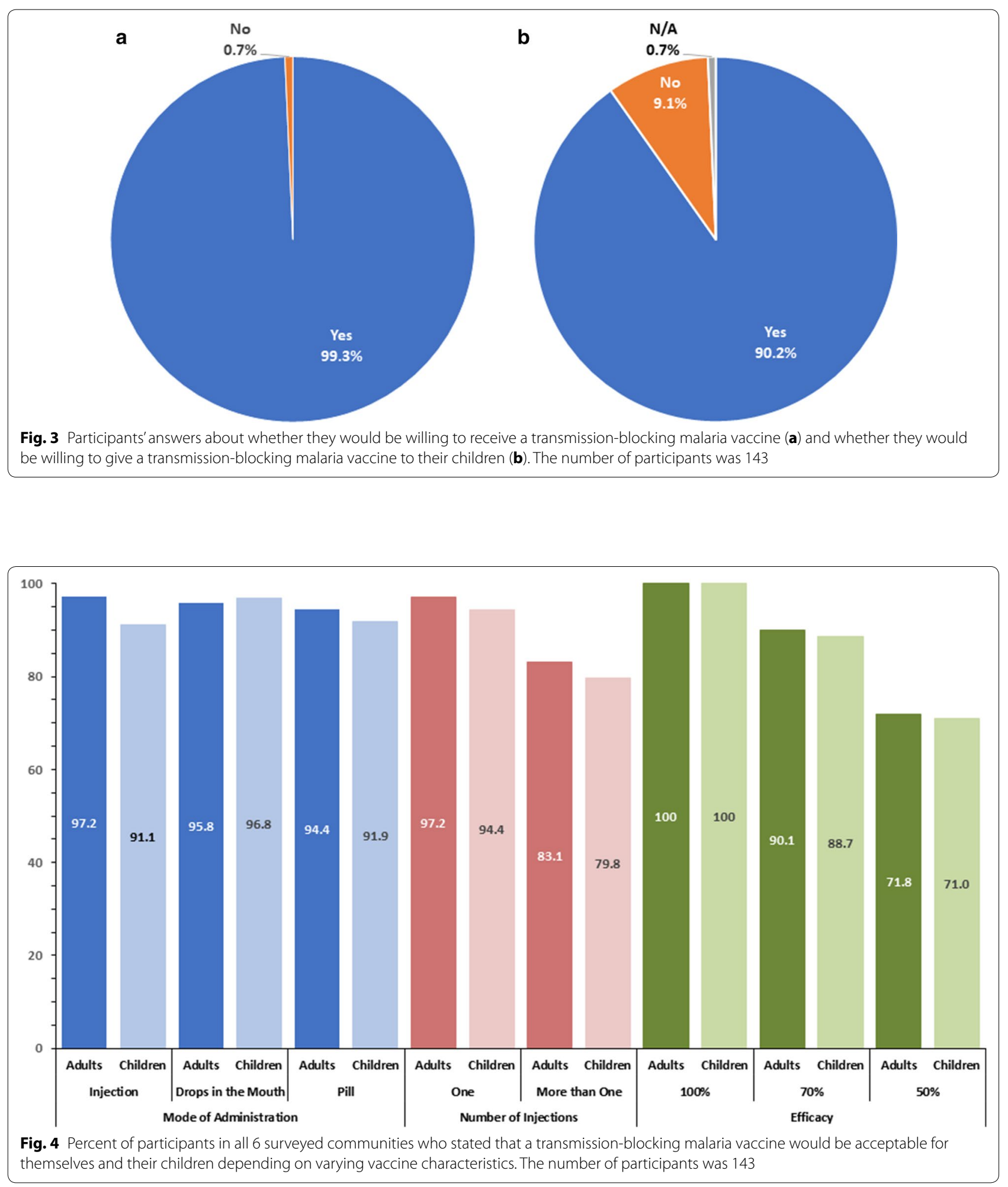
Table 2 Participants' willingness to receive a transmission-blocking malaria vaccine depending on varying vaccine characteristics

\begin{tabular}{|c|c|c|c|c|c|c|c|}
\hline & $\begin{array}{l}\text { Cahuide } \\
(n=48)\end{array}$ & $\begin{array}{l}12 \text { de Abril } \\
(n=17)\end{array}$ & $\begin{array}{l}\text { La Habana } \\
(n=13)\end{array}$ & $\begin{array}{l}\text { San José de } \\
\text { Lupuna }(n=27)\end{array}$ & $\begin{array}{l}\text { Santa Rita } \\
(n=21)\end{array}$ & $\begin{array}{l}\text { San Pedro } \\
(n=15)\end{array}$ & $\begin{array}{l}\text { Total (or Aver- } \\
\text { age) }(n=141)\end{array}$ \\
\hline \multicolumn{8}{|l|}{ Cost } \\
\hline Only if free & $22(45.8 \%)$ & $3(17.6 \%)$ & $4(30.8 \%)$ & $11(40.7 \%)$ & $8(38.1 \%)$ & $7(46.7 \%)$ & $55(39.0 \%)$ \\
\hline Willing to pay & $26(54.2 \%)$ & $14(82.4 \%)$ & $9(69.2 \%)$ & $16(59.3 \%)$ & $13(61.9 \%)$ & $8(53.3 \%)$ & $86(61.0 \%)$ \\
\hline Average price $(\mathrm{S} . /)^{\mathrm{a}}$ & 8.7 & 9.4 & 10.0 & 2.6 & 4.3 & 2.8 & 6.6 \\
\hline Modified price $(S . /)^{a}$ & 4.7 & 7.7 & 6.9 & 1.5 & 2.7 & 1.5 & 4.0 \\
\hline \multirow[t]{2}{*}{ Price range $(S . /)^{\mathrm{a}}$} & $2-30$ & $2-30$ & $5-20$ & $1-5$ & $1-5$ & $1-5$ & $1-5$ \\
\hline & $\begin{array}{l}\text { Cahuide } \\
(n=48)\end{array}$ & $\begin{array}{l}12 \text { de Abril } \\
(n=17)\end{array}$ & $\begin{array}{l}\text { La Habana } \\
(n=13)\end{array}$ & $\begin{array}{l}\text { San José de } \\
\text { Lupuna }(n=27)\end{array}$ & $\begin{array}{l}\text { Santa Rita } \\
(n=22)\end{array}$ & $\begin{array}{l}\text { San Pedro } \\
(n=15)\end{array}$ & $\begin{array}{l}\text { Total } \\
(n=142)\end{array}$ \\
\hline \multicolumn{8}{|c|}{ Acceptable modes of administration for adults } \\
\hline Injection & $47(97.9 \%)$ & $17(100 \%)$ & $13(100 \%)$ & 27 (100\%) & $21(95.5 \%)$ & $13(86.7 \%)$ & $138(97.2 \%)$ \\
\hline Drops in the mouth & $46(95.8 \%)$ & $17(100 \%)$ & $13(100 \%)$ & $25(92.6 \%)$ & $21(95.5 \%)$ & $14(93.3 \%)$ & $136(95.8 \%)$ \\
\hline \multirow[t]{2}{*}{ Pill } & $44(91.7 \%)$ & $16(94.1 \%)$ & $12(92.3 \%)$ & $26(96.3 \%)$ & $21(95.5 \%)$ & $15(100 \%)$ & $134(94.4 \%)$ \\
\hline & $\begin{array}{l}\text { Cahuide } \\
(n=39)\end{array}$ & $\begin{array}{l}12 \text { de Abril } \\
(n=17)\end{array}$ & $\begin{array}{l}\text { La Habana } \\
(n=11)\end{array}$ & $\begin{array}{l}\text { San José de } \\
\text { Lupuna }(n=25)\end{array}$ & $\begin{array}{l}\text { Santa Rita } \\
(n=19)\end{array}$ & $\begin{array}{l}\text { San Pedro } \\
(n=13)\end{array}$ & $\begin{array}{l}\text { Total } \\
(n=124)\end{array}$ \\
\hline \multicolumn{8}{|c|}{ Acceptable modes of administration for children } \\
\hline Injection & $34(87.2 \%)$ & $16(94.1 \%)$ & 10 (90.9\%) & $23(92.0 \%)$ & $18(94.7 \%)$ & $12(92.3 \%)$ & $113(91.1 \%)$ \\
\hline Drops in the mouth & $37(94.9 \%)$ & $17(100 \%)$ & $11(100 \%)$ & $24(96.0 \%)$ & $19(100 \%)$ & $12(92.3 \%)$ & $120(96.8 \%)$ \\
\hline \multirow[t]{2}{*}{ Pill } & $35(89.7 \%)$ & $17(100 \%)$ & $10(90.9 \%)$ & $22(88.0 \%)$ & $17(89.5 \%)$ & $13(100 \%)$ & $114(91.9 \%)$ \\
\hline & $\begin{array}{l}\text { Cahuide } \\
(n=48)\end{array}$ & $\begin{array}{l}12 \text { de Abril } \\
(n=17)\end{array}$ & $\begin{array}{l}\text { La Habana } \\
(n=13)\end{array}$ & $\begin{array}{l}\text { San José de } \\
\text { Lupuna }(n=27)\end{array}$ & $\begin{array}{l}\text { Santa Rita } \\
(n=22)\end{array}$ & $\begin{array}{l}\text { San Pedro } \\
(n=15)\end{array}$ & $\begin{array}{l}\text { Total } \\
(n=142)\end{array}$ \\
\hline \multicolumn{8}{|c|}{ Number of injections acceptable for adults } \\
\hline One & 47 (97.9\%) & $16(94.1 \%)$ & $13(100 \%)$ & $27(100 \%)$ & $22(100 \%)$ & $13(86.7 \%)$ & $138(97.2 \%)$ \\
\hline \multirow[t]{2}{*}{ More than one } & $38(79.2 \%)$ & $14(82.4 \%)$ & $13(100 \%)$ & $25(92.6 \%)$ & $17(77.3 \%)$ & $11(73.3 \%)$ & $118(83.1 \%)$ \\
\hline & $\begin{array}{l}\text { Cahuide } \\
(n=39)\end{array}$ & $\begin{array}{l}12 \text { de Abril } \\
(n=17)\end{array}$ & $\begin{array}{l}\text { La Habana } \\
(\mathrm{n}=11)\end{array}$ & $\begin{array}{l}\text { San José de } \\
\text { Lupuna }(n=25)\end{array}$ & $\begin{array}{l}\text { Santa Rita } \\
(n=19)\end{array}$ & $\begin{array}{l}\text { San Pedro } \\
(n=13)\end{array}$ & $\begin{array}{l}\text { Total } \\
(n=124)\end{array}$ \\
\hline \multicolumn{8}{|c|}{ Number of injections acceptable for children } \\
\hline One & $35(89.7 \%)$ & $17(100 \%)$ & 10 (90.9\%) & $24(96.0 \%)$ & $18(94.7 \%)$ & $13(100 \%)$ & $117(94.4 \%)$ \\
\hline \multirow[t]{2}{*}{ More than one } & $28(71.8 \%)$ & $15(88.2 \%)$ & $10(90.9 \%)$ & $22(88.0 \%)$ & $13(68.4 \%)$ & $11(84.6 \%)$ & 99 (79.8\%) \\
\hline & $\begin{array}{l}\text { Cahuide } \\
(n=48)\end{array}$ & $\begin{array}{l}12 \text { de Abril } \\
(n=17)\end{array}$ & $\begin{array}{l}\text { La Habana } \\
(n=13)\end{array}$ & $\begin{array}{l}\text { San José de } \\
\text { Lupuna }(n=27)\end{array}$ & $\begin{array}{l}\text { Santa Rita } \\
(n=22)\end{array}$ & $\begin{array}{l}\text { San Pedro } \\
(n=15)\end{array}$ & $\begin{array}{l}\text { Total } \\
(n=142)\end{array}$ \\
\hline \multicolumn{8}{|c|}{ Acceptable efficacy for adults (\%) } \\
\hline 100 & $48(100 \%)$ & $17(100 \%)$ & $13(100 \%)$ & $27(100 \%)$ & $22(100 \%)$ & $15(100 \%)$ & $142(100 \%)$ \\
\hline 70 & $43(89.6 \%)$ & $15(88.2 \%)$ & $12(92.3 \%)$ & $25(92.6 \%)$ & $21(95.5 \%)$ & $12(80.0 \%)$ & $128(90.1 \%)$ \\
\hline \multirow[t]{2}{*}{50} & $29(60.4 \%)$ & $12(70.6 \%)$ & $10(76.9 \%)$ & $22(81.5 \%)$ & $17(77.3 \%)$ & $12(80.0 \%)$ & $102(71.8 \%)$ \\
\hline & $\begin{array}{l}\text { Cahuide } \\
(n=39)\end{array}$ & $\begin{array}{l}12 \text { de Abril } \\
(n=17)\end{array}$ & $\begin{array}{l}\text { La Habana } \\
(n=11)\end{array}$ & $\begin{array}{l}\text { San José de } \\
\text { Lupuna }(n=25)\end{array}$ & $\begin{array}{l}\text { Santa Rita } \\
(n=19)\end{array}$ & $\begin{array}{l}\text { San Pedro } \\
(n=13)\end{array}$ & $\begin{array}{l}\text { Total } \\
(n=124)\end{array}$ \\
\hline \multicolumn{8}{|c|}{ Acceptable efficacy for children (\%) } \\
\hline 100 & $39(100 \%)$ & $17(100 \%)$ & $11(100 \%)$ & $25(100 \%)$ & $19(100 \%)$ & $13(100 \%)$ & $124(100 \%)$ \\
\hline 70 & $35(89.7 \%)$ & $15(88.2 \%)$ & 10 (90.9\%) & $23(92.0 \%)$ & $17(89.5 \%)$ & $10(76.9 \%)$ & $110(88.7 \%)$ \\
\hline 50 & $22(56.4 \%)$ & $12(70.6 \%)$ & $8(72.7 \%)$ & $21(84.0 \%)$ & $15(78.9 \%)$ & $10(76.9 \%)$ & $88(71.0 \%)$ \\
\hline
\end{tabular}

a Prices are listed in Peruvian soles. In July-August 2014, S./1 $\approx \$ 0.36$ USD. Average price is the mean of the prices cited by those who were willing to pay for the vaccine. Modified price is the mean of all prices, including the price of $\mathrm{S} . / 0$ cited by those who were only willing to receive the vaccine if it were free. Six participants were childless and 12 responded that they did not wish to respond on behalf of their adult children who could make their own vaccination decisions, accounting for $\mathrm{n}=142$ for adult responses and $\mathrm{n}=124$ for responses related to children 
was the only one to respond no. All others responded affirmatively $(n=124)$ or said that the question was not applicable either because they had no children or their children were grown $(n=18)$. Despite understanding that the vaccine would provide no protection to them individually, participants nearly universally accepted the idea of a transmission-blocking malaria vaccine for themselves and their children.

When asked about willingness to pay, 39.0\% responded that they would only receive the vaccine if it were free. Sixty-one percent responded that they would be willing to pay a mean price of 6.6 Peruvian soles (about US $\$ 2.21$ at the time of the study). Acceptability of the vaccine waned marginally depending on mode of administration, with injections being preferred for adults $(138 / 142,97.2 \%)$ and drops in the mouth preferred for children (120/124, 96.8\%). When asked about willingness to receive the vaccine if it were necessary to administer multiple injections, reported acceptability decreased to $83.1 \%$ for adults and $79.8 \%$ for children. When vaccine efficacy was presumed to be $70 \%$, reported acceptability decreased to $90.1 \%$ for adults and $88.7 \%$ for children; when presumed efficacy was reduced to $50 \%$, reported acceptability decreased to 71.8 and $71.0 \%$ for adults and children, respectively (Fig. 4 and Table 2).

Only one of 143 participants in the study considered the rationale for a transmission-blocking malaria vaccine to be unacceptable; unfortunately, information was not available regarding why she responded negatively. This respondent was a homemaker and mother living in one of the Nanay River Basin communities. Unlike $99.3 \%$ of participants interviewed, this participant reported never having had malaria. She also reported that 2 of her 3 children had never had malaria. This lack of personal experience with a disease that had otherwise greatly impacted her community might explain her reluctance to accept a TBV.

Given the almost-nil frequency of TBV rejection in the study, it was not possible to directly test the hypothesis that decreased malaria exposure leads to decreased TBV acceptability. Instead three alternate hypotheses were chosen for testing, which may serve as a proxy for the effect of personal malaria exposure on vaccine acceptability: a high degree of malaria exposure will make an individual more likely to (1) pay for a TBV; (2) agree to receive multiple doses of a TBV; and (3) agree to receive a less effective vaccine as compared to someone with little or no personal malaria exposure. For the purposes of this study, malaria exposure was categorized as none $(0$ prior cases of malaria), low (1-4 prior cases), or high (5 or more cases, including those who reported too many cases to count or remember).
Statistical analysis using Fisher's exact test revealed no relationship between malaria exposure and willingness to pay $(\mathrm{p}=0.92)$; price willing to pay $(\mathrm{p}=0.48)$; or price range category of none (0 soles), low (1-9 soles), or high (10 or more soles) $(\mathrm{p}=0.51)$. Further, level of prior malaria exposure was not predictive of willingness to receive multiple vaccine doses $(\mathrm{p}=0.85)$ or willingness to receive a 70 or $50 \%$ effective vaccine $(\mathrm{p}=0.81$ and $\mathrm{p}=0.79$, respectively). All $\mathrm{p}$-values remained statistically insignificant when malaria exposure was further recategorized as simply high ( 5 or more cases) or low (4 or fewer cases).

Asked about willingness to receive a transmissionblocking malaria vaccine, participants in all 6 communities gave answers that demonstrated both a clear understanding that such a vaccine would not protect the vaccinated individual from becoming infected and clear support for receiving a vaccine with those characteristics (Table 3).

\section{Discussion}

In this study of the acceptability of a herd-immunityfocused, transmission-blocking malaria vaccine that does not directly protect recipients against malaria infection, we found that members of six malaria-hypoendemic communities in the Amazon River basin in Loreto, Peru, overwhelmingly reported such a vaccine to be acceptable for themselves and their children. Although some malaria researchers and policy-makers in the industrialized world have considered a transmission-blocking vaccine (TBV) to be altruistic and, therefore, perhaps less acceptable, the results presented here indicate that affected populations may consider the protection of others a compelling rationale to vaccinate themselves and their children against malaria, especially in light of the prevention and treatment options currently available, primarily LLIN distribution plus opportune diagnosis and treatment. Further, as previously noted, the concept of vaccines aimed at herd immunity to prevent disease transmission in populations is well established [4, 29, 30, 59]. Acceptability of a TBV remained high among the study participants despite characteristics such as having to pay for the vaccine themselves and the potential need for multiple injections.

In 2011, the RTS,S vaccine developed by GlaxoSmithKline (GSK), which targets a sporozoite surface protein, reached phase III trials in sub-Saharan Africa. Modest vaccine efficacy has been documented across multiple clinical trials in adults, children, and infants [60-62]. More recently, safety and tolerance testing has been performed with whole aseptic, purified, cryopreserved Pf sporozoites (PfSPZ) [63-65]. Asexual blood stage vaccine candidates have been proposed since the 1980s, when 
Table 3 Reasons cited by participants for the acceptability of a transmission-blocking malaria vaccine, demonstrating motives and understanding of important concepts

\author{
Theme 1: A TBV might be a superior intervention to current prevention and treatment options \\ "It's necessary for not infecting other people; my daughter has gastritis from getting sick so much!"-36 year old male, 12 de Abril \\ "So that [the mosquitoes] perhaps won't transmit, for prevention; besides, it's better than the pills." -53 year old male, Santa Rita \\ "To not contaminate other people and so that it's easier to get healthy. You can't put up with this."-26 year old female, 12 de Abril \\ "It's better than the pills that give us allergies."-27 year old female, La Habana \\ "It would give time, and there would be someone [healthy] left in the house that could still attend to the sick."- 34 year old female, La Habana \\ Theme 2: The concept of transmission blockade is understood and acceptable. \\ "So that it doesn't go on increasing, to not infect the rest."-29 year old female, San José de Lupuna \\ "I wouldn't want malaria to keep on growing, and this avoids that it passes on to all the others."-40 year old female, Santa Rita \\ "The mosquito will no longer transmit it; if we don't, it will keep on infecting." - 65 year old male, San Pedro \\ "I'm protecting it from transmitting to everybody else."-39 year old female, Cahuide \\ "So that my children don't get sick and pass it on to all the other children."-20 year old female, Cahuide \\ Theme 3: The altruistic nature of a TBV is not a deterrent \\ "We're avoiding that my partner or a child or grandchild that comes to visit gets sick."-75 year old male, Cahuide \\ "So that the disease doesn't pass on, to protect the rest. Perhaps it will be that it doesn't do me any good, but it's for others." - 35 year old male, La Habana \\ "For protecting other people, there's no problem with that." 57 year old male, San Pedro \\ "So there wouldn't be so much transmission to other people. I would be protecting my children more than anything."-33 year old female, Cahuide \\ "To protect everyone else from the illness."-38 year old male, Santa Rita \\ Theme 4: Appropriate application of a TBV could lead to regional elimination of malaria \\ "The mosquito won't transmit to other people anymore; if we all vaccinate ourselves, this malaria won't exist anymore — 42 year old female, Cahuide \\ "The mosquito will no longer transmit to other people, and we won't have malaria anymore."- 57 year old female, San José de Lupuna \\ "It's better that we're not infecting one another anymore. We'd have to vaccinate everyone, then."-75 year old male, Santa Rita
}

Open-ended responses have been categorized by theme

SPf66 initially gave promising results that were ultimately not replicable [66-68]. Many other asexual blood stage candidates have been proposed and tested with limited success, including MSP1, MSP2, RSEA, and AMA1, stimulating the suggestion of a combined vaccine with both pre-erythrocyte and erythrocyte stage components, as well as a vaccine directed against the whole parasite in the asexual blood stage [69-76].

Given only modest success with current vaccines aimed at the sporozoite and asexual blood stages of malaria parasites, a transmission-blocking vaccine could serve as a key component of malaria control and elimination strategies. Even in low transmission areas, such as Peru, Brazil, and Colombia, published data demonstrate that asymptomatic malaria parasitaemia and gametocytaemia contribute to Plasmodium transmission [77-80]. These data suggest that a TBV, even if only moderately effective, would contribute to reducing transmission from individuals with subclinical infection.

This study has several limitations. First, the study participants were selected from an ongoing study cohort of individuals under the auspices of the ICEMR-Amazonía. All members of the study have monthly blood samples taken and analysed for the presence of Plasmodium species. Those that are positive are treated free of charge at the local health post. Because of their participation in this study, our respondents probably had a better understanding of malaria transmission, pathogenesis, and current treatment limitations than members of other communities with high levels of malaria infection. Self-reports of malaria history are more likely accurate: because of the ICEMR, the majority of these reports likely derive from parasite-based diagnoses rather than episodes of generalized fever or illness. Such universal reports of infection support the assertion that these and similar communities in the region experience endemic malaria and demonstrate the degree to which the illness weighs on community consciousness $[35,48-50,58]$. It is also possible that the familiarity of these communities with the ICEMR and study team members led to social desirability bias: because of their personal relationships with study team members, survey participants may have been more trusting, more anxious to please the surveyors, and expressed higher levels of altruism than residents of a community with no previous knowledge of the ICEMR or team. Future work could repeat this study design in a different population to assess whether acceptance remains high in the setting of low levels of laboratory-proven exposure to malarial disease and where residents do not have an existing relationship with the study team. 
Second, the values of family, community, and selflessness were clearly seen to be of critical importance for the members of these six communities and served as motivations for receiving a transmission-blocking malaria vaccine. It is possible that not every community with endemic malaria holds the value of community in equally high regard. This would likely be reflected in a lower number of people that would elect to receive a vaccine that would not protect them directly but would rather serve to benefit the community as a whole.

Third, this study was carried out in a region where malaria transmission is not intense. Results of a similar survey might be different even in other parts of Peru, such as in the nearby city of Iquitos, where malaria is far less common, and Lima, which is entirely unaffected; survey results could likewise differ in places with higher disease burden, such as in malaria holoendemic regions of sub-Saharan Africa and Papua New Guinea. This could impact success at achieving malaria elimination following the introduction of a TBV. Any one or a combination of these reasons could help explain why participants in the current study expressed greater willingness to accept a TBV than participants of studies elsewhere were to accept a malaria vaccine that would prevent human infection $[81,82]$.

Given these limitations, this study should be adapted and expanded in communities with varying degrees of malaria exposure. Until such studies are carried out, it would be difficult to make any claim for the generalizability of the results of this study. This would also help us better evaluate a new hypothesis that degree of malaria exposure correlates with TBV acceptability. With only two subjects having no personal experience with malaria, the present study was unable to demonstrate any such relationship, should it exist. It would also be profitable to directly compare the acceptability of transmission-blocking and infection-preventing malaria vaccines in this and other communities, as this was not done in this study. In addition, cultural and educational factors may affect TBV acceptability in other malaria-endemic regions; similar studies in other places should take such factors into account.

Finally, this study did not assess the potential impact of adverse events (AEs) on willingness to receive the TBV. It is widely known that parents and caregivers may refuse to allow their children to be vaccinated for fear of AEs even when such fear is unwarranted [83]. Little is known about the exact nature of the relationship between perceived probability or severity of an $\mathrm{AE}$ and vaccine acceptance. Nevertheless, it seems reasonable to assume that acceptance would decrease with increasing frequency and severity of expected AEs, a phenomenon not addressed by this study.
Several studies have commented on community perceptions of and concerns about infection-preventing malaria vaccines $[81,82]$. When reviewing the literature, however, it appears that the present study is the first to assess attitudes toward the idea of a transmission-blocking malaria vaccine in a malaria-hypoendemic region. Future studies should include qualitative methods such as in-depth interviews to better understand participant responses to the types of quantitative questions reported here and to explore in greater depth potential facilitators and barriers to vaccine acceptance among this population. Such research will be crucial to effective promotion of an eventual TBV to create anti-malaria herd immunity in populations.

\section{Additional files}

Additional file 1. Study questionnaire translated into English.

Additional file 2. All responses to survey question \#18: why people would or would not be willing to receive or allow their children to be vaccinated with a vaccine that confers no personal protection (a TBV).

\section{Authors' contributions}

SEW conceived of the study, developed the protocol with input from other authors, supervised data collection, analysed the data with input from other authors, and wrote the first draft of the manuscript. SAH provided guidance to SEW on protocol and instrument development, data collection and data analysis. He made extensive contributions to drafting and revising the manuscript. GM contributed to development of the protocol, supervised SEW and the local data collection team, and contributed to drafting and revising the manuscript. AL, MG, and DG contributed to the development of the protocol and to drafting and revising the manuscript. JV provided mentorship and guidance to SEW throughout the development and realization of the study. He contributed to the study conception, protocol development, data analysis, and drafting and revising the manuscript. All authors read and approved the final manuscript.

\section{Author details}

${ }^{1}$ Division of Infectious Diseases, Department of Medicine, University of California, San Diego School of Medicine, 9500 Gilman Drive 0760, Biomedical Research Facility Room 4A16, La Jolla, CA 92093-0760, USA. ${ }^{2}$ Department of International Health, Johns Hopkins Bloomberg School of Public Health, 615 N. Wolfe St. E5030, Baltimore, MD 21205, USA. ${ }^{3}$ Facultad de Medicina Humana, Universidad Nacional de la Amazonia Peruana, Iquitos, Peru. ${ }^{4}$ Malaria and Leishmaniasis Division, Instituto de Medicina Tropical Alexander von Humboldt, Av. Honorio Delgado 430, San Martín de Porres, Lima, Peru. ${ }^{5}$ Department of Cellular and Molecular Sciences, Faculty of Sciences and Laboratory of Research and Development, Universidad Peruana Cayetano Heredia, Lima, Peru.

\section{Acknowledgements}

We wish to thank Paula Maguiña of the University of California for her scientific, logistical, and ethics compliance support that were essential for the completion of this work, the International Centres for Excellence in Malaria Research (ICEMR) for their support and pre-existing work in the region that made this project possible, the populations of Cahuide, 12 de Abril, La Habana, San José de Lupuna, Santa Rita and San Pedro for their participation, and Shirle Chanchari Soria and Eliseo Ramírez Paredes for their help in organization and garnering community support. Thanks also to Dan Salmon for his reading of and suggestions on the manuscript.

\section{Competing interests}

The authors declare that they have no competing interests. 
Ethics approval and consent to participate

Not applicable.

\section{Funding}

This work was supported by United States Public Health Service Grants U19AI089681, D43TW007120, R01AI067727, and K24AI068903 (JMV), all from the US National Institutes of Health.

\section{Publisher's Note}

Springer Nature remains neutral with regard to jurisdictional claims in published maps and institutional affiliations.

Received: 29 December 2017 Accepted: 18 April 2018

Published online: 27 April 2018

\section{References}

1. Carter R, Chen D. Malaria transmission blocked by immunisation with gametes of the malaria parasite. Nature. 1976;263:57-60.

2. Gwadz RW. Successful immunization against the sexual stages of Plasmodium gallinaceum. Science. 1976;193:1150-1.

3. Kaslow DC, Quakyi IA, Syin C, Raum MG, Keister DB, Coligan JE, et al. A vaccine candidate from the sexual stage of human malaria that contains EGF-like domains. Nature. 1988;333:74-6.

4. PATH Malaria Vaccine Initiative Workshop on Malaria Transmission-Blocking Vaccines: Summary and Outcomes. 2010. http://www.malariavaccine. org/sites/www.malariavaccine.org/files/content/resource/files/TBVworkshop-summary-20140331.pdf. Accessed Jun 2010

5. Jamrozik E, de la Fuente-Nunez V, Reis A, Ringwald P, Selgelid MJ. Ethical aspects of malaria control and research. Malar J. 2015:14:518.

6. Moorthy VS, Good MF, Hill AV. Malaria vaccine developments. Lancet. 2004;363:150-6.

7. Carter R, Mendis KN, Miller LH, Molineaux L, Saul A. Malaria transmissionblocking vaccines-how can their development be supported? Nat Med. 2000;6:241-4.

8. Walgate R. Quest for malaria vaccine revs up, but much work remains. Bull World Health Organ. 2001;79:1002-4.

9. Vaccines DeWeerdt S. The take-home lesson. Nature. 2012;484:S24-5.

10. Kumar R, Angov E, Kumar N. Potent malaria transmission-blocking antibody responses elicited by Plasmodium falciparum Pfs 25 expressed in Escherichia coli after successful protein refolding. Infect Immun. 2014;82:1453-9.

11. Kaslow DC, Bathurst IC, Lensen T, Ponnudurai T, Barr PJ, Keister DB. SaCcharomyces cerevisiae recombinant Pfs 25 adsorbed to alum elicits antibodies that block transmission of Plasmodium falciparum. Infect Immun. 1994;62:5576-80.

12. Zou L, Miles AP, Wang J, Stowers AW. Expression of malaria transmissionblocking vaccine antigen Pfs 25 in Pichia pastoris for use in human clinical trials. Vaccine. 2003:21:1650-7.

13. Arakawa T, Komesu A, Otsuki H, Sattabongkot J, Udomsangpetch R, Matsumoto $Y$, et al. Nasal immunization with a malaria transmission-blocking vaccine candidate, Pfs 25 , induces complete protective immunity in mice against field isolates of Plasmodium falciparum. Infect Immun. 2005:73:7375-80.

14. Mlambo G, Kumar N, Yoshida S. Functional immunogenicity of baculovirus expressing Pfs25, a human malaria transmission-blocking vaccine candidate antigen. Vaccine. 2010;28:7025-9.

15. Jones RM, Chichester JA, Mett V, Jaje J, Tottey S, Manceva S, et al. A plant-produced Pfs25 VLP malaria vaccine candidate induces persistent transmission blocking antibodies against Plasmodium falciparum in immunized mice. PLOS ONE. 2013;8:e79538.

16. Tsuboi T, Takeo S, Iriko H, Jin L, Tsuchimochi M, Matsuda S, et al. Wheat germ cell-free system-based production of malaria proteins for discovery of novel vaccine candidates. Infect Immun. 2008;76:1702-8.

17. Tsuboi T, Takeo S, Sawasaki T, Torii M, Endo Y. An efficient approach to the production of vaccines against the malaria parasite. Methods Mol Biol. 2010;607:73-83.
18. Miura K, Takashima E, Deng B, Tullo G, Diouf A, Moretz SE, et al. Functional comparison of Plasmodium falciparum transmission-blocking vaccine candidates by the standard membrane-feeding assay. Infect Immun. 2013;81:4377-82.

19. Gregory JA, Li F, Tomosada LM, Cox CJ, Topol AB, Vinetz JM, et al. Algaeproduced pfs 25 elicits antibodies that inhibit malaria transmission. PLoS ONE. 2012;7:e37179.

20. Gregory JA, Topol AB, Doerner DZ, Mayfield S. Alga-produced cholera toxin-Pfs 25 fusion proteins as oral vaccines. Appl Environ Microbiol. 2013;79:3917-25

21. MalERA Consultative Group on Vaccines. A research agenda for malaria eradication: vaccines. PLoS Med. 2011;8:e1000398.

22. Rener J, Graves PM, Carter R, Williams JL, Burkot TR. Target antigens of transmission-blocking immunity on gametes of Plasmodium falciparum. J Exp Med. 1983;158:976-81.

23. Mendis KN, Munesinghe YD, de Silva YN, Keragalla I, Carter R. Malaria transmission-blocking immunity induced by natural infections of Plasmodium vivax in humans. Infect Immun. 1987:55:369-72.

24. Ponnudurai T, van Gemert GJ, Bensink T, Lensen AH, Meuwissen JH. Transmission blockade of Plasmodium falciparum: its variability with gametocyte numbers and concentration of antibody. Trans R Soc Trop Med Hyg. 1987;81:491-3.

25. Ranawaka MB, Munesinghe YD, de Silva DM, Carter R, Mendis KN. Boosting of transmission-blocking immunity during natural Plasmodium vivax infections in humans depends upon frequent reinfection. Infect Immun. 1988:56:1820-4.

26. Kaslow DC. Immunogenicity of Plasmodium falciparum sexual stage antigens: implications for the design of a transmission blocking vaccine. Immunol Lett. 1990;25:83-6.

27. Kaslow DC, Bathurst IC, Barr PJ. Malaria transmission-blocking vaccines. Trends Biotechnol. 1992;10:388-91.

28. Kaslow DC. Transmission-blocking immunity against malaria and other vector-borne diseases. Curr Opin Immunol. 1993:5:557-65.

29. Orenstein W, Seib K. Mounting a good offense against measles. N Engl J Med. 2014;371:1661-3.

30. Garnett GP, Waddell HC. Public health paradoxes and the epidemiological impact of an HPV vaccine. J Clin Virol. 2000;19:101-11.

31. Maartens G, Celum C, Lewin SR. HIV infection: epidemiology, pathogenesis, treatment, and prevention. Lancet. 2014;384:258-71.

32. Roberts DR, Laughlin LL, Hsheih P, Legters LJ. DDT, global strategies, and a malaria control crisis in South America. Emerg Infect Dis. 1997;3:295-302.

33. Aramburu Guarda J, Ramal Asayag C, Witzig R. Malaria reemergence in the Peruvian Amazon region. Emerg Infect Dis. 1999;5:209-15.

34. Roper MH, Carrion Torres RS, Cava Goicochea CG, Andersen EM, Aramburu Guarda JS, Calampa C, et al. The epidemiology of malaria in an epidemic area of the Peruvian Amazon. Am J Trop Med Hyg. 2000;62:247-56.

35. Torres KJ, Castrillon CE, Moss EL, Saito M, Tenorio R, Molina DM, et al. Genome-level determination of Plasmodium falciparum blood-stage targets of malarial clinical immunity in the Peruvian Amazon. J Infect Dis. 2015;211:1342-51.

36. Barbosa S, Gozze AB, Lima NF, Batista CL, Bastos Mda S, Nicolete VC, et al. Epidemiology of disappearing Plasmodium vivax malaria: a case study in rural Amazonia. PLoS Negl Trop Dis. 2014;8:e3109.

37. Parker BS, Paredes Olortegui M, Penataro Yori P, Escobedo K, Florin D, Rengifo Pinedo $\mathrm{S}$, et al. Hyperendemic malaria transmission in areas of occupation-related travel in the Peruvian Amazon. Malar J. 2013;12:178.

38. Harvey SA, Lam Y, Martin NA, Olortegui MP. Multiple entries and exits and other complex human patterns of insecticide-treated net use: a possible contributor to residual malaria transmission? Malar J. 2017;16:265.

39. Newell I, Wiskin C, Anthoney J, Meza G, de Wildt G. Preventing malaria in the Peruvian Amazon: a qualitative study in Iquitos, Peru. Malar J. 2018;17:31.

40. Rosas-Aguirre A, Gamboa D, Manrique P, Conn JE, Moreno M, Lescano AG, et al. Epidemiology of Plasmodium vivax malaria in Peru. Am J Trop Med Hyg. 2016;95(6 Suppl):133-44.

41. Prussing C, Moreno M, Saavedra MP, Bickersmith SA, Gamboa D, Alava F, et al. Decreasing proportion of Anopheles darlingi biting outdoors between long-lasting insecticidal net distributions in peri-lquitos, Amazonian Peru. Malar J. 2018;17:86 
42. Quinones ML, Norris DE, Conn JE, Moreno M, Burkot TR, Bugoro H, et al. Insecticide resistance in areas under investigation by the International Centers of Excellence for Malaria Research: a challenge for malaria control and elimination. Am J Trop Med Hyg. 2015;93(3 Suppl):69-78.

43. Martin TCS, Vinetz JM. Asymptomatic Plasmodium vivax parasitaemia in the low-transmission setting: the role for a population-based transmission-blocking vaccine for malaria elimination. Malar J. 2018;17:89.

44. da Silva-Nunes M, Moreno M, Conn JE, Gamboa D, Abeles S, Vinetz JM, et al. Amazonian malaria: asymptomatic human reservoirs, diagnostic challenges, environmentally driven changes in mosquito vector populations, and the mandate for sustainable control strategies. Acta Trop. 2011;121:281-91.

45. Cotter C, Sturrock HJ, Hsiang MS, Liu J, Phillips AA, Hwang J, et al. The changing epidemiology of malaria elimination: new strategies for new challenges. Lancet. 2013;382:900-11.

46. Feachem RG, Phillips AA, Hwang J, Cotter C, Wielgosz B, Greenwood $B M$, et al. Shrinking the malaria map: progress and prospects. Lancet. 2010:376:1566-78.

47. Kamya MR, Arinaitwe E, Wanzira H, Katureebe A, Barusya C, Kigozi SP, et al. Malaria transmission, infection, and disease at three sites with varied transmission intensity in Uganda: implications for malaria control. Am J Trop Med Hyg. 2015;92:903-12.

48. Chuquiyauri R, Penataro P, Brouwer KC, Fasabi M, Calderon M, Torres S, et al. Microgeographical differences of Plasmodium vivax relapse and reinfection in the Peruvian Amazon. Am J Trop Med Hyg. 2013;89:326-38.

49. Kosek M, Yori PP, Gilman RH, Calderon M, Zimic M, Chuquiyauri R, et al. High degree of Plasmodium vivax diversity in the Peruvian Amazon demonstrated by tandem repeat polymorphism analysis. Am J Trop Med Hyg. 2012:86:580-6.

50. Chuquiyauri R, Paredes M, Penataro P, Torres S, Marin S, Tenorio A, et al. Socio-demographics and the development of malaria elimination strategies in the low transmission setting. Acta Trop. 2012;121:292-302.

51. Perkins TA, Garcia AJ, Paz-Soldan VA, Stoddard ST, Reiner RC Jr, VazquezProkopec G, et al. Theory and data for simulating fine-scale human movement in an urban environment. J R Soc Interface. 2014;11:20140642.

52. Wesolowski A, Eagle N, Tatem AJ, Smith DL, Noor AM, Snow RW, et al. Quantifying the impact of human mobility on malaria. Science. 2012;338:267-70.

53. O'Sullivan M, Kenilorea G, Yamaguchi Y, Bobogare A, Losi L, Atkinson JA, et al. Malaria elimination in Isabel Province, Solomon Islands: establishing a surveillance-response system to prevent introduction and reintroduction of malaria. Malar J. 2011;10:235.

54. Singhanetra-Renard A. Malaria and mobility in Thailand. Soc Sci Med. 1993;37:1147-54

55. Somboon P, Aramrattana A, Lines J, Webber R. Entomological and epidemiological investigations of malaria transmission in relation to population movements in forest areas of north-west Thailand. Southeast Asian J Trop Med Public Health. 1998;29:3-9.

56. Pindolia DK, Garcia AJ, Wesolowski A, Smith DL, Buckee CO, Noor AM, et al. Human movement data for malaria control and elimination strategic planning. Malar J. 2012;11:205.

57. Yori PP, Lee G, Olortegui MP, Chavez CB, Flores JT, Vasquez AO, et al. Santa Clara de Nanay: the MAL-ED cohort in Peru. Clin Infect Dis. 2014;59(Suppl 4):S310-6.

58. Roshanravan B, Kari E, Gilman RH, Cabrera L, Lee E, Metcalfe J, et al. Endemic malaria in the Peruvian Amazon region of lquitos. Am J Trop Med Hyg. 2003;69:45-52.

59. Nunes JK, Woods C, Carter T, Raphael T, Morin MJ, Diallo D, et al. Development of a transmission-blocking malaria vaccine: progress, challenges, and the path forward. Vaccine. 2014;32:5531-9.

60. Alonso PL, Sacarlal J, Aponte JJ, Leach A, Macete E, Aide P, et al. Duration of protection with RTS, S/AS02A malaria vaccine in prevention of Plasmodium falciparum disease in Mozambican children: single-blind extended follow-up of a randomised controlled trial. Lancet. 2005;366:2012-8.

61. Rts SCTP, Agnandji ST, Lell B, Fernandes JF, Abossolo BP, Methogo BG, et al. A phase 3 trial of RTS, S/AS01 malaria vaccine in African infants. N Engl J Med. 2012;367:2284-95.
62. Olotu A, Fegan G, Wambua J, Nyangweso G, Awuondo KO, Leach A, et al. Four-year efficacy of RTS, S/AS01E and its interaction with malaria exposure. N Engl J Med. 2013;368:1111-20.

63. Hodgson SH, Juma E, Salim A, Magiri C, Kimani D, Njenga D, et al. Evaluating controlled human malaria infection in Kenyan adults with varying degrees of prior exposure to Plasmodium falciparum using sporozoites administered by intramuscular injection. Front Microbiol. 2014;5:686.

64. Shekalaghe $S$, Rutaihwa M, Billingsley PF, Chemba M, Daubenberger CA, James ER, et al. Controlled human malaria infection of Tanzanians by intradermal injection of aseptic, purified, cryopreserved Plasmodium falciparum sporozoites. Am J Trop Med Hyg. 2014;91:471-80.

65. Seder RA, Chang LJ, Enama ME, Zephir KL, Sarwar UN, Gordon IJ, et al. Protection against malaria by intravenous immunization with a nonreplicating sporozoite vaccine. Science. 2013;341:1359-65.

66. Patarroyo ME, Amador R, Clavijo P, Moreno A, Guzman F, Romero P, et al. A synthetic vaccine protects humans against challenge with asexual blood stages of Plasmodium falciparum malaria. Nature. 1988;332:158-61.

67. Nosten F, Luxemburger C, Kyle DE, Ballou WR, Wittes J, Wah E, et al. Randomised double-blind placebo-controlled trial of SPf66 malaria vaccine in children in northwestern Thailand. Shoklo SPf66 Malaria Vaccine Trial Group. Lancet. 1996;348:701-7.

68. Marshall E. Serious setback for Patarroyo vaccine. Science. 1996;273(5282):1652.

69. Pombo DJ, Lawrence G, Hirunpetcharat C, Rzepczyk C, Bryden M, Cloonan $\mathrm{N}$, et al. Immunity to malaria after administration of ultra-low doses of red cells infected with Plasmodium falciparum. Lancet. 2002:360:610-7.

70. Pinzon-Charry A, Good MF. Malaria vaccines: the case for a whole-organism approach. Expert Opin Biol Ther. 2008;8:441-8.

71. Moorthy VS, Diggs C, Ferro S, Good MF, Herrera S, Hill AV, et al. Report of a consultation on the optimization of clinical challenge trials for evaluation of candidate blood stage malaria vaccines, 18-19 March 2009, Bethesda, MD. USA. Vaccine. 2009;27:5719-25.

72. McCarthy JS, Good MF. Whole parasite blood stage malaria vaccines: a convergence of evidence. Hum Vaccin. 2010;6:114-23.

73. Good MF. A whole parasite vaccine to control the blood stages of Plasmodium: the case for lateral thinking. Trends Parasitol. 2011;27:335-40.

74. McCarthy JS, Marjason J, Elliott S, Fahey P, Bang G, Malkin E, et al. A phase 1 trial of MSP2-C1, a blood-stage malaria vaccine containing 2 isoforms of MSP2 formulated with Montanide(R) ISA 720. PLoS ONE. 2011;6:e24413.

75. Engwerda CR, Minigo G, Amante FH, McCarthy JS. Experimentally induced blood stage malaria infection as a tool for clinical research. Trends Parasitol. 2012;28:515-21.

76. McCarthy JS, Griffin PM, Sekuloski S, Bright AT, Rockett R, Looke D, et al. Experimentally induced blood-stage Plasmodium vivax infection in healthy volunteers. J Infect Dis. 2013;208:1688-94.

77. Gonzalez JM, Olano V, Vergara J, Arevalo-Herrera M, Carrasquilla G, Herrera $\mathrm{S}$, et al. Unstable, low-level transmission of malaria on the Colombian Pacific Coast. Ann Trop Med Parasitol. 1997;91:349-58.

78. Cucunuba ZM, Guerra AP, Rahirant SJ, Rivera JA, Cortes LJ, Nicholls RS Asymptomatic Plasmodium spp. infection in Tierralta, Colombia. Mem Inst Oswaldo Cruz. 2008;103:668-73.

79. Van den Eede P, Soto-Calle VE, Delgado C, Gamboa D, Grande T, Rodriguez $\mathrm{H}$, et al. Plasmodium vivax sub-patent infections after radical treatment are common in Peruvian patients: results of a 1-year prospective cohort study. PLOS ONE. 2011;6:e16257.

80. Vinetz JM, Gilman RH. Asymptomatic Plasmodium parasitemia and the ecology of malaria transmission. Am J Trop Med Hyg. 2002;66:639-40.

81. Bingham A, Gaspar F, Lancaster K, Conjera J, Collymore Y, Ba-Nguz A. Community perceptions of malaria and vaccines in two districts of Mozambique. Malar J. 2012;11:394.

82. Ojakaa DI, Ofware P, Machira YW, Yamo E, Collymore Y, Ba-Nguz A, et al. Community perceptions of malaria and vaccines in the South Coast and Busia regions of Kenya. Malar J. 2011;10:147.

83. Larson HJ, Jarrett C, Eckersberger E, Smith DM, Paterson P. Understanding vaccine hesitancy around vaccines and vaccination from a global perspective: a systematic review of published literature, 2007-2012. Vaccine. 2014;32:2150-9. 